\title{
Metodología para la evaluación alimentaria y nutricional desde una perspectiva de equidad
}

\section{Methodology for food and nutritional evaluation from a perspective of equity}

Núm. 5 (2015), pp. 35-62

Álvarez-Castaño, Luz Stella*1

Goez-Rueda, Juan Diego*2

Díaz-García, Juliana* 3

Quintero-Morales, María Teresa*4

Recibido: enero, 2015

Aceptado: octubre, 2015

JEL Clasif: $\mathrm{H}_{43}, \mathrm{H}_{53}, \mathrm{I}_{31}, \mathrm{I}_{3} 8$

DOI: $10.5944 /$ reppp.5.2015.13957

\footnotetext{
*1 Luz Stella Álvarez-Castaño. PHD en Salud Pública. Profesora Titular Escuela de Nutrición y Dietética - Universidad de Antioquia (Colombia). E-mail: luz.alvarez@udea.edu.co

*2 Juan Diego Goez Rueda. Mg Ciencias de la alimentación y nutrición humana. Profesor de catedra Escuela de Nutrición y Dietética - Universidad de Antioquia (Colombia). E-mail: diegogoez@gmail.com *3 Juliana Díaz García. Nutricionista Dietista. Profesora de catedra Escuela de Nutrición y Dietética Universidad de Antioquia(Colombia). E-mail: juliana.diaz@udea.edu.co

*4 María Teresa Quintero Morales. Mg Ciencias de la alimentación y nutrición humana. Profesora de catedra Escuela de Nutrición y Dietética - Universidad de Antioquia (Colombia). E-mail: maite. quinteromorales@gmail.com
} 


\title{
Resumen
}

En América Latina, las nuevas políticas sociales de lucha contra la pobreza tienen como centro de atención los programas de alimentación y nutrición cuyo impacto social se evalúa en la mayoría de los casos en función de sus resultados biológicos o de criterios administrativos como el cumplimiento de selección de beneficiarios. El modelo que proponemos combina métodos cualitativos y cuantitativos e incorpora la evaluación de la estructura, los procesos y los resultados en las siguientes dimensiones: seguridad alimentaria y nutricional, derecho a la alimentación, construcción de ciudadanía, participación ciudadana en las políticas, territorialidad en la planeación, empoderamiento de la mujer y la gestión del programa. En la evaluación de resultados incluye la percepción de los diferentes actores como los destinatarios de los programas y los comprometidos en su ejecución.

Palabras Clave: evaluación; políticas públicas; programas; alimentación y nutrición; equidad

\begin{abstract}
In Latin America, the new social policies to fight on poverty have food and nutrition programs as the spotlight, whose social impact is assessed in most cases based on their biological outcomes or administrative criteria such as compliance with selection beneficiaries. Our proposed model to evaluate nutritional programs combines qualitative and quantitative methods and incorporates the evaluation of the structure, processes and outcomes in the following dimensions: food and nutrition security, right to food, citizenship, territorial planning, empowerment of women and program management. The evaluation results include the perception of different actors such as recipients of programs and those involved in its implementation.
\end{abstract}

Key Words: evaluation; public policy; programs; food and nutrition; equity 


\section{Introducción}

El presente artículo plantea una metodología para la evaluación de programas alimentarios y nutricionales poblacionales, que tengan como objetivo el desarrollo humano, el mejoramiento de la calidad de vida y el bienestar social.

Siguiendo la propuesta de De Miguel Díaz, partimos de considerar que «La tarea del evaluador no puede limitarse a una simple elección de metodologías y métodos para obtener evidencia... se necesita de manera imprescindible una teoría que justifique y explique los procedimientos y las prácticas que en cada caso se llevan a cabo». Por tanto, todo diseño metodológico para la evaluación de un programa social, debe incluir una noción de programa, una noción de evaluación, referentes conceptuales y referentes epistemológicos, «que le den sentido a lo qué hace un evaluador, cómo lo hace y, sobre todo, para qué» (Diaz, 2000).

A continuación se encuentra, una breve descripción del desarrollo de las políticas alimentarias y nutricionales durante el periodo desarrollista, el neoliberalismo y sus diferentes transformaciones con la crisis. Posteriormente se mencionan los antecedentes en materia de evaluación de programas nutricionales, luego se plantea el fundamento epistemológico, así como el concepto de evaluación que sustenta esta propuesta. Además se desarrollan las dimensiones sobre las cuales se fundamenta la metodología presentada y finalmente se describe la propuesta metodológica.

\section{Antecedentes de las políticas alimentarias y nutricionales}

El desarrollo de programas nutricionales poblacionales tiene una amplia tradición en América Latina. Según el Banco Mundial estas intervenciones se pueden agrupar en: programas de transferencias condicionadas, suplementación y complementación, fortificación, educación nutricional, agricultura familiar y subsidio a los precios de los alimentos (Bourges, Bengoa, \& O-Donell, s.d.).

En Colombia, los programas nutricionales iniciaron en la década de los 40, cuando el Estado empezó a asumir su responsabilidad en las políticas sociales transfiriendo recursos a la Iglesia católica para que continuara el suministro de los alimentos a los pobres e iniciara la implementación de los primeros restaurantes escolares (Krause, 1963) (Bejarano-Roncancio, 2009). En 1960 con la Alianza para el Progreso, estrategia promovida por Estados Unidos (Krause, 1963), se aumentó la cobertura de los programas alimentarios y se mitigaron algunas dificultades de la población en situación de vulnerabilidad, gracias a la donación de los alimentos o la venta a bajos precios. Sin embargo, a finales de los 70, las ayudas disminuyeron por la crisis del petróleo, deteriorando la situación alimentaria en la mayoría de países pobres.

Hasta la década de 1980, Latinoamérica siguió el modelo de Industrialización por sustitución de Importaciones (Bejarano-Roncancio, 2009) bajo el cual Colombia creó múltiples programas para atender algunas necesidades básicas, entre ellas el cuidado y la alimentación de los niños y creó entidades como el Instituto Colombiano de Bienestar Familiar encargado del direccionamiento y ejecución de los programas de bienestar social (Bejarano-Roncancio, 2009) (Mancilla, Alvarez, \& Pérez, 2012).

Revista de Evaluación de Programas y Políticas Públicas | Núm. 5 (2015), pp.35-62 
En los años 80 y 90 la firma del Consenso de Washington y las reformas económicas tendientes a implementar el modelo neoliberal, condujeron a los gobiernos a disminuir la inversión en programas de protección social y a crear, en coordinación con los organismos supranacionales, una plataforma de focalización de beneficiarios en los «más pobres de los pobres», que respondía a la necesidad de confrontar la masificación de los problemas sociales con fondos recortados (Vilas, 1997) (Serrano, 2005). En Colombia este modelo de política social se ha denominado «Manejo Social de Riesgo» (Jørgensen \& Holzmann, 2003) bajo el cual se han implementado en las últimas décadas la mayoría de los programas sociales, incluyendo los nutricionales (Departamento Nacional de Planeación - SINERGIA - Colombia, 2008).

En la actualidad existe en América Latina una estrategia de protección social que difiere en algunos aspectos del modelo neoliberal y que algunos han denominado «la perspectiva de la inversión social» (Lopreite, 2012), basada en el desarrollo del capital humano, con tres premisas básicas: la noción de que la educación es el pilar del futuro de las economías, una creciente atención hacia la inversión en el futuro centrado en la educación y salud de los niños y la idea de que invertir en capital humano, pensando en el futuro, es beneficioso para la comunidad en su totalidad (Jenson, 2010). A pesar de las diferencias entre países, los programas coinciden en el enfoque de derechos y en cuanto a sus estrategias, en el uso de transferencias monetarias condicionadas y en tener a la mujer y los niños como sus principales beneficiarios y titulares de derechos. Con esta perspectiva se desarrollan en la actualidad muchos de los programas sociales y nutricionales de la región.

\section{La evaluación de programas nutricionales}

La evaluación de programas sociales utiliza métodos y técnicas propias de la investigación social, aunque se reconoce como un campo disciplinario independiente con objetivos y retos específicos (Romero \& Díaz, 2002) (Diaz, 2000). En América Latina han predominado los enfoques cuantitativos que privilegian el análisis del impacto y los resultados de los programas. El enfoque de planeación y evaluación de mayor difusión en el continente ha sido el Marco Lógico desarrollado por el ILPES, división de la CEPAL (9), basado en la creación de programas con una lógica determinista (Ortegon, Pacheco, \& Prieto, 2005) (Banco Mundial, 2004). Como lo señalan algunos autores este modelo y otros similares ignora a los titulares o destinatarios de los programas así como a otros actores claves en su implementación, quienes deberían ser el eje central de la evaluación (Creswell, 2003).

Para el caso de los programas de alimentación y nutrición en Colombia y en general en América Latina la evaluación se ha centrado principalmente en la verificación del cumplimiento de metas de cobertura establecidas en los Planes de Desarrollo, enfatizando en la focalización de los destinatarios, la adecuada ejecución de los recursos y escasamente en el cambio del estado nutricional de los beneficiarios (Departamento Nacional de Planeación -SINERGIA- Colombia, 2008) (Ortiz, Isaza, \& Ramírez, 2010) (Nuñez \& Cuesta, 2007); algunas de las evaluaciones se han realizado implementando el Marco Lógico, pero la mayoría sin un enfoque metodológico explícito (Álvarez-Castaño, Pérez-Isaza, Góez-Rueda, Rivera-Jaramillo, \& Peña-Ochoa, 2014). 
Igual que sucede en otras políticas públicas muchas de las evaluaciones de programas alimentarios y nutricionales desconocen las percepciones de los actores y las condiciones contextuales de los programas. El énfasis en la verificación cuantitativa de resultados centrada en la cobertura, excluye la consideración de los factores contextuales y de los aspectos políticos que permean los procesos de las políticas públicas, el contexto de los programas, la realidad de sus beneficiarios y al propio proceso de evaluación (Roth, 2009) (Nirenberg, Brawerman, \& Ruiz, 2003) (De Souza, Goncalves de Assis, \& Ramos de Souza, 2005).

Construir enfoques que superen estos rasgos de las evaluaciones en el campo alimentario y nutricional es importante por diferentes razones, que tienen que ver con la naturaleza y la trascendencia de los problemas que se enfrentan, los recursos invertidos, pero especialmente las nuevas metas sociales que se busca cumplir. En relación a la naturaleza del problema, porque sin superar los desafíos tradicionales de déficits alimentarios, nuestra sociedad se enfrenta ahora a situaciones como el sobrepeso y las enfermedades crónicas relacionadas con la alimentación, lo cual está demandando cada vez más intervenciones complejas con alta destinación de recursos. Pero tal vez la mayor importancia de nuevos enfoques de evaluación en este campo, radica, como se señalaba anteriormente, en que hoy se espera que estos programas sean los catalizadores del desarrollo humano y social en sus territorios. Esto significa que promuevan el bienestar, la participación y unos nuevos referentes de ciudadanía y de relaciones entre estado y ciudadanos. Como lo afirma Serrano «la política social no solo opera como dispensadora de servicios sociales o reparadora de los desperfectos que genera el mercado, sino también un sistema constructor de integración, ciudadanía y comunidad nacional» (Serrano, 2005).

Respecto al campo específico de la evaluación de programas y política sociales estos nuevos enfoques se hacen necesarios para complementar las perspectivas cuantitativas con las percepciones de los actores involucrados y para dimensionar otros alcances y efectos en las esferas sociales y políticas que los programas tienen en los territorios más allá de sus efectos inmediatos.

La propuesta que se presenta a continuación busca contribuir a la construcción de nuevos enfoques para la evaluación de programas alimentarios y nutricionales, que superen algunos de los rasgos biológicos y cuantitativos explicados anteriormente. Su presentación está organizada de la siguiente manera: Una descripción de los referentes conceptuales los cuales incluyen el fundamento epistemológico y la noción de evaluación adoptada. Posteriormente se desarrollan las dimensiones de seguridad alimentaria y nutricional, el derecho a la alimentación, la construcción de ciudadanía, la participación ciudadana en las políticas, la territorialidad en la planeación de las políticas, el empoderamiento de la mujer y por último la gestión del programa. Finalmente se describe la metodología y la matriz de la propuesta.

\section{Referentes conceptuales}

\subsection{Fundamento epistemológico}

Creswell y Nirenberg, retoman tres paradigmas para clasificar las corrientes que siguen las evaluaciones de programas sociales: el post positivista, el constructivista y el emancipatorio; esta clasificación parte de la premisa de que la evaluación ha estado fuertemente influenciada por los paradigmas científicos predominantes en la investigación social (Creswell, 2003) (Nirenberg, Brawerman, \& Ruiz, 2003). 
Para nuestro diseño metodológico retomamos elementos del paradigma constructivista y del emancipatorio, su combinación en evaluación se clasifica como modelos alternativos.

El paradigma constructivista se basa en el reconocimiento de las realidades sociales y del comportamiento, como construcciones mentales. Guba y Lincoln llaman a este proceso dialéctica -hermenéutica- para interpretar los hechos desde la perspectiva de los actores, que en últimas son los verdaderos protagonistas de la realidad (Guba \& Lincoln, 1989). En este paradigma se valoriza lo particular, lo variable, el interés local, el compromiso de los individuos y sus potencialidades personales (De Souza, Goncalves de Assis, \& Ramos de Souza, 2005).

El paradigma emancipatorio por su parte, considera que los procesos de investigación y evaluación y quienes los dirigen deben hacer aportes a asuntos sociales tan importantes como la reducción de la inequidad, la opresión, la dominación y la alienación (Creswell, 2003). Por eso en las evaluaciones realizadas bajo este paradigma, las conclusiones y recomendaciones emergen de los agentes clave, es decir, no son sólo del evaluador sino que se construyen con las personas participantes del programa, su voz se convierte en una sola voz para la transformación y el cambio (De Souza, Goncalves de Assis, \& Ramos de Souza, 2005).

\subsection{Un concepto sobre evaluación}

Asumimos el siguiente concepto: «La evaluación de programas sociales es un proceso de recolección sistemática de información sobre una práctica social, que tiene la intención de promover una mejor comprensión de su desarrollo, medir sus resultados y contribuir a la toma de decisiones estratégicas para el alcance de sus objetivos» (Magalhães, 2014). La evaluación debe ser efectuada en conjunto con los actores involucrados en el desarrollo e implementación de las intervenciones. Estos alcances de la evaluación se pueden lograr a través de la investigación empírica sistemática en el área con la interacción entre los datos cuantitativos y cualitativos del proceso de aplicación a nivel local o territorial, capturando así la complejidad de los programas y contribuyendo al aprendizaje y el cambio efectivo (Magalhães, 2014).

Así mismo, entendemos que la evaluación tal y como lo plantean algunos autores, además de promover la integración de las dimensiones objetiva y subjetiva de los programas debe dar voz a sus actores y convertirlos en sujetos activos para las modificaciones y transformaciones que se requieren (Minayo \& Cruz-Neto, 1999).

Este concepto de evaluación también implica un fundamento ético. De acuerdo con De Miguel, los programas no sólo tienen que ser coherentes desde la perspectiva técnica, su consistencia no solo debe ser interna, sino que su calidad debe evaluarse además, por su compromiso en la resolución de los problemas sociales y en la lucha en favor de una sociedad más justa e igualitaria (Diaz, 2000). Por tanto como lo plantean otros autores, el diseño de nuevas propuestas de evaluación de programas sociales, debe partir del entendimiento de estos como «sistemas reflexivos y de la complejidad del contexto en el que se inserta con sus respectivas estrategias abarcantes e intersectoriales de enfrentamiento de las desigualdades sociales... Este abordaje problematiza los objetivos y la finalidad de las intervenciones, su dependencia y estrecha vinculación con decisiones políticas que influencian y reorientan estrategias frente a múltiples puntos de vista, efectos y resultados» (Weiss, 1995). 


\section{Dimensiones}

El presente diseño metodológico está fundamentado en la interrelación de siete dimensiones: Seguridad alimentaria y nutricional, derecho a la alimentación, construcción de ciudadanía, participación ciudadana, perspectiva territorial de la planeación, empoderamiento de la mujer y gestión del programa. Consideramos que esta interrelación se constituye en un núcleo indivisible sobre el que se deben inspirar las políticas alimentarias, si realmente se pretende consolidar estrategias de bienestar social sustentables a largo plazo para superar las inequidades sociales. A continuación se hace referencia al contenido de cada dimensión.

\subsection{Seguridad alimentaria y nutricional}

Retomamos la definición adoptada en el Conpes Social 113 de 2008 que define la Seguridad alimentaria y nutricional (SAN) como, «la disponibilidad suficiente y estable de alimentos, el acceso y el consumo oportuno y permanente de los mismos en cantidad, calidad e inocuidad por parte de todas las personas, bajo condiciones que permitan su adecuada utilización biológica, para llevar una vida saludable y activa» (República de Colombia. Departamento Nacional de planeación, 2007).

Tradicionalmente se ha considerado que la SAN tiene varios ejes: a) Disponibilidad de alimentos, está relacionada con el suministro suficiente de estos frente a los requerimientos de la población y depende fundamentalmente de la producción y la importación; b) Acceso físico y económico a los alimentos, se refiere a los alimentos que puede obtener o comprar una familia, una comunidad o un país; c) Consumo de alimentos, se refiere a los alimentos que comen las personas y está relacionado con la selección de los mismos, las creencias, las actitudes y las prácticas; d) Aprovechamiento o utilización biológica, hace alusión a cómo y cuánto aprovecha el cuerpo humano los alimentos que consume y cómo los convierte en nutrientes para ser asimilados por el organismo; y e) Calidad e inocuidad, es el conjunto de características de los alimentos que garantizan que sean aptos para el consumo humano, que exigen el cumplimiento de una serie de condiciones y medidas necesarias durante la cadena agroalimentaria hasta el consumo y el aprovechamiento de los mismos (República de Colombia. Departamento Nacional de planeación, 2007).

Los ejes de la SAN no se materializan en forma separada, involucra a la familia, la sociedad civil y fundamentalmente al Estado. Para evaluar esta dimensión en las políticas y programas se trata de establecer sus efectos en términos de estado nutricional, prácticas alimentarias, calidad y cantidad de la alimentación consumida. Estas condiciones a su vez están relacionadas con los recursos familiares destinados a la alimentación, la equidad en la distribución de la alimentación al interior del hogar y la garantía de no padecimiento de hambre debido a restricciones económicas del hogar. Dependiendo del tipo de política o programa que se esté analizando, también es posible considerar los efectos de las intervenciones en términos de la producción y la disponibilidad de alimentos sanos y nutritivos para la población beneficiaria o titular de los derechos. 


\subsection{El derecho a la alimentación}

El derecho a la alimentación hace parte del sistema internacional de derechos humanos (SIDH), dentro de los denominados derechos sociales, económicos y culturales. De acuerdo con Marshall se han reconocido desde mediados del siglo XX y en el camino recorrido por la mayoría de países occidentales industrializados ha sido el último grupo de derechos alcanzados por los individuos y legitimados por las sociedades y los estados. Desde su reconocimiento, los organismos que hacen parte del SIDH han propuesto diferentes mecanismos para su implementación, garantía y exigibilidad, en un trabajo arduo para dotar de contenido los enunciados generales firmados por los gobiernos de los diferentes países.

Se define como «el derecho humano a alimentarse de forma digna». Significa que todos los miembros de la sociedad tienen derecho al acceso permanente a alimentos no solo suficientes en cantidad, sino también adecuados en calidad nutricional, inocuos y culturalmente aceptables para la persona que los consume. Igualmente es fundamental que el acceso a los alimentos sea estable y sostenible ecológica y socialmente» (Pautassi, 2009).La realización de este derecho es multidimensional y requiere una respuesta coordinada desde varios ámbitos e instituciones. Además está vinculada con otros derechos humanos como el derecho a la propiedad y el acceso a la justicia, los derechos laborales y el derecho a la educación (Vivero \& Ramirez, 2009).

La alimentación como derecho debe ser un principio que guíe las políticas alimentarias y su evaluación, porque permite que todos los seres humanos y en particular quienes padecen hambre, se conviertan en sujeto titular y no objeto de la asistencia alimentaria. Se fundamenta en la idea de que el hambre y la inseguridad alimentaria son producto de la inequitativa distribución de los recursos y del escaso poder político de sus víctimas. Es decir, la noción de derecho busca dotar de titularidades a quienes padecen hambre y desvelar el carácter político y económico del problema, más allá de sus dimensiones nutricionales y de salud.

Desde esta perspectiva, los programas sociales, incluyendo los alimentarios y nutricionales, se consideran eficaces solo si forman parte de una estrategia de desarrollo económico y social que tenga como objetivo central la realización de los derechos de las personas; como lo afirma Lopreite, en la medida en que este tipo de programas tienen el objetivo de convertirse en universales y permanentes, a partir de transformaciones importantes en el régimen de bienestar social, lograrían que el pilar fundamental de la protección social, sea la ciudadanía, y no la posición social de los individuos (Lopreite, 2012).

Algunas de las características que dan cuenta de si las políticas y programas alimentarios y nutricionales están inspirados en el derecho a la alimentación son: hay una clara definición sobre qué bienes y servicios se garantizan a los titulares del derecho y en qué condiciones; no se establecen mecanismos que limiten el acceso real a ciertos grupos sociales, es decir los criterios de ingreso y permanencia son los más amplios posibles; las condicionalidades no se convierten en mecanismos velados de exclusión; son progresivos, es decir no se reducen y por el contrario aumentan los recursos y la calidad de los bienes y servicios; aumenta la cobertura; se crean respaldos normativos para garantizar la estabilidad de las políticas y programas y se generan instancias para el control social que permita exigir el cumplimiento de lo establecido en la normatividad. 


\section{5•3. La construcción de ciudadanía}

Según Rego 2008, la ciudadanía se constituye en un marco de derechos, privilegios y deberes que configura un sistema de reciprocidades determinantes de la naturaleza de las relaciones de correspondencia de los individuos entre sí y con el Estado. Su enraizamiento en la vida colectiva como sentimiento, cultura y sistema de referencias valorativa se convierte en medida fundamental del grado de democratización alcanzado por una sociedad (Rego, 2008).

Las políticas sociales usualmente llegan a los ciudadanos en forma de la prestación de bienes y servicios gestionados por el estado; en nuestro caso usualmente en la distribución o entrega de alimentos y/o subsidios para su adquisición. Pero es claro que además de la provisión de bienes estas políticas tienen otras finalidades y producen consecuencias para el estado, los ciudadanos y la sociedad en general. (Serrano, 2005)

Aunque otras entidades hagan parte de los sistemas de protección social y participen de los programas sociales, es claro que el estado es su actor principal como conductor y ejecutor (Serrano, 2005). Por eso entre los fines últimos de cualquier política social está la generación y preservación de un espacio social de pertenencia a la comunidad sociopolítica (Lechner, 2002). Se trata no sólo de la provisión de servicios o bienes en caso de necesidad, sino de una construcción social que le permite a los ciudadanos reconocerse como parte de una sociedad, con un destino colectivo compartido (Serrano, 2005).

El papel que deben jugar las políticas alimentarias y nutricionales en la construcción de ciudadanía es diverso. Se trata de considerar que como ciudadanos, todos y todas tendríamos el derecho a la alimentación de manera universal y progresiva, sin restricciones derivadas de criterios de inclusión como por ejemplo demostrar los más precarios niveles de pobreza, ni de mecanismos clientelares de asignación de cupos. Igualmente se construye ciudadanía cuando los servidores públicos conciben a los ciudadanos como titulares de derecho y no beneficiarios de servicios transitorios sujetos a condicionalidades o a manejos arbitrarios en los presupuestos. Además cuando se parte de que los bienes y servicios que proveen los programas son de la mejor calidad y se suministran, de manera oportuna y cumpliendo los más altos estándares.

\subsection{Participación ciudadana en las políticas públicas}

La participación de los ciudadanos en las políticas públicas es definida como «el proceso a través del cual distintos sujetos sociales y colectivos, en función de sus respectivos intereses y de la lectura que hacen de su entorno, intervienen en la marcha con el fin de mantener, transformar o reformar el orden social y político» (Velásquez, 2003). Se trata de un proceso que es fin y medio al mismo tiempo. Es decir, las personas participan porque buscan alcanzar objetivos específicos y al mismo tiempo la participación es un mecanismo para la construcción de la democracia. (Velásquez, 2003). Cuando hablamos de participación ciudadana nos referimos a un proceso fundamentado en la Constitución Nacional, que no sólo atañe a la elección de los cuerpos representativos sino a un proceso social amplio y comprehensivo, que se refiere de manera general a los diversos mecanismos e instancias con los que cuentan los ciudadanos para incidir en las estructuras estatales y en las políticas públicas (Chac, 2008). 
Por ser la participación ciudadana un fin pero también el camino para la construcción de las políticas públicas, algunos autores señalan la profunda relación entre tres elementos: la democracia, la participación y los derechos ciudadanos. Se requiere la participación ciudadana para el fortalecimiento de la democracia, si, pero en clave de desarrollo y de garantía y realización de derechos. Es decir, se trata de una participación que sea efectiva en generación de políticas públicas que mejoren la calidad de vida de la población y superen la exclusión social y la desigualdad. De esta manera habría que romper la tendencia en el continente que concibe la participación como confinada a ciertas políticas sociales y al margen en las políticas económicas (Chac 2008). En síntesis, la perspectiva de derechos como fin de la participación ciudadana sería uno de los elementos centrales en la construcción de la democracia no sólo en el campo político sino en las esferas económica y social.

En el plano de las políticas alimentarias y nutricionales la participación social sería el mecanismo a través del cual los ciudadanos intervienen en el diseño, ejecución y evaluación de los programas y son informados sobre los recursos y su distribución. Pero también, como ha ocurrido en otros países, se trata de una participación en los diferentes niveles territoriales en los que se planifican, evalúan y se distribuyen los recursos para construir unas nuevas políticas que garanticen el derecho a la alimentación, es decir, la nación, los departamentos y los municipios. Igualmente, es una participación en niveles porque se trata de que las organizaciones sociales constituidas para ejercer el control de los programas y las políticas alimentarias y nutricionales, hagan parte de procesos de movilización social y planeación participativa en su entorno.

\subsection{Territorialidad en la planeación de las políticas}

A partir de las reformas político-administrativas derivadas de la Constitución de 1991, los procesos de descentralización y participación ciudadana reconocieron los territorios -básicamente a las regiones y los municipios - como los espacios por excelencia para la planeación y ejecución de las políticas públicas. Este reconocimiento se debió, entre otras cosas, a la evidencia de la crisis de la planificación centralizada y vertical y a sus escasos logros en materia de desarrollo social.

De acuerdo con Echeverry, el enfoque territorial tiene el sentido no sólo de superar las limitaciones de la planeación sectorial, ni de hacer más eficiente la inversión pública, sino que se trata de una manera distinta de concebir y construir el desarrollo, por su carácter multidimensional «El reconocimiento de esta característica debería llevar a estrategias que superen metas netamente sectoriales y a abordar la integralidad de las múltiples variables que conforman una sociedad más participativa y corresponsable en la gestión de su propio desarrollo» (Echeverry-Pinilla). La intencionalidad no es el abandono de lo sectorial sino que se propone el territorio como un espacio para la articulación de la acción estatal en sus múltiples facetas. Lo territorial cobra importancia no sólo porque ser el espacio de concreción de los problemas sino como potencialidad para su resolución.

En el plano de lo político, lo territorial se concibe como el lugar en que se conjuga la acción del Estado que sigue siendo el eje articulador y ejecutor de las políticas públicas, pero en relación con otros actores privados, sociales y comunitarios cuya dinámica de interacción le imprime características singulares a estas políticas (Naranjo-Giraldo, 
Lopera-Morales, \& Granada-Vahos, 2009). Desde esta perspectiva, las políticas públicas no son concebidas como el mandato vertical de las instituciones estatales sino el resultado de la acción y los intereses de múltiples actores asentados en los territorios.

Lo territorial cobra importancia no sólo como espacio para reformular el desarrollo social y económico y las políticas públicas, sino como el lugar para la acción política y social de los actores que lo pueden hacer posible. De tal manera que cuando hablamos de territorio o enfoque territorial nos referimos al espacio físico generalmente municipios, zonas o comunas pero además al conjunto de redes, relaciones y conexiones que en ellos se realizan. En el campo alimentario y nutricional esto implica que la planeación y la toma de decisiones sobre las políticas y los programas no se lleven a cabo sólo en el nivel nacional ni por un solo sector. Se trata de una planeación que conjugue los diferentes niveles y que permita que en el nivel local las políticas y programas sean coherentes con la historia, las culturas, los actores y las dinámicas organizativas. La dimensión territorial se concretaría entonces en mayor autonomía de los entes subnacionales, flexibilidad para adaptar las políticas y programas a realidades locales y mayor nivel de integración y coordinación con otros programas asentados en los territorios y desarrollados por los diversos actores sociales. De esta manera se construirían objetivos de desarrollo comunes más fáciles de alcanzar.

La dimensión territorial de la planeación también implicaría que los programas alimentarios dinamicen las prácticas locales de producción y comercialización de alimentos en perspectiva de equidad. Es decir, en lo posible que se compre a campesinos de la región, producción elaborada con prácticas sostenibles, se fortalezca las dinámicas de comercialización tradicional que empoderen a los eslabones más débiles de la cadena de suministro de alimentos.

\subsection{Empoderamiento de la mujer}

Desde una perspectiva de equidad de género se acuña el término empoderamiento para denotar la búsqueda de poderes solidarios, transformadores, generativos, contrarios a poderes de dominación o poderes excluyentes. El poder es entonces una fuente de emancipación, que permite posicionar y visibilizar a las mujeres para que en plenitud de condiciones participen en la construcción de la sociedad que históricamente ha sido excluyente (León, 2013).

Se define el empoderamiento de la mujer como «un proceso personal y político, cuyas aristas personales, intimas, corporales, no pueden desvincularse de sus connotaciones políticas, de impugnación de las relaciones de poder vividas en el seno de relaciones familiares, en donde los sujetos viven cotidianamente y a su vez son parte del orden social» (León, 2013). El empoderamiento, es la estrategia más importante de las mujeres para ganar posición por sí mismas en forma individual o colectiva, mediante acciones participativas y transformadoras (León, Magdalena (comp), 1998), y como lo mencionan otros autores, se refiere a «la toma de conciencia de sus propios derechos, con el fin de participar desde una posición más sólida en la toma de decisiones y poder influir en ellas» (Murguialday, Pérez, \& Eizagirre, s.d.).

Existen diferentes momentos del empoderamiento dependiendo del tiempo, las acciones y los logros, el rol de los actores, la metodología y la estructura organizativa 
que tenga. El empoderamiento individual, se refiere a un aumento de autoconfianza y autonomía; el empoderamiento colectivo, se da cuando se logra planear y ejecutar proyectos con perspectiva de equidad de género, permitiendo la transformación de las personas, estructuras y sistemas; es decir, el empoderamiento político fortalece y relaciona lo individual y lo colectivo y consolida la capacidad transformadora, de negociación y de decisión (León, Magdalena (comp), 1998).

El empoderamiento de la mujer como marco de análisis en las políticas públicas, tiene un recorrido internacional, nacional y comunitario que puede fundamentarse desde una mirada feminista que lo concibe como un proceso de emancipación, o desde el enfoque desarrollado por los organismos internacionales como las Naciones Unidas quienes lo consideran un elemento indispensable para el desarrollo, la igualdad y la paz (León, 2013). En la actualidad es parte de los objetivos del milenio «Promover la equidad de género y el empoderamiento» y dentro de las estrategias más extendidas para cumplir este objetivo se encuentran los programas de transferencias condicionadas (Comisión Económica para América Latina y el Caribe, 2010).

Estos programas mencionan entre sus alcances el empoderamiento de la mujer por varias vías; el aumentar la inversión en capital humano de niñas y niños por igual, tiene un efecto positivo sobre el bienestar de las niñas y mantiene una estabilidad de ingresos en los hogares más vulnerables (Comisión Económica para América Latina y el Caribe, 2010). Sin embargo, este empoderamiento es limitado y ambivalente, ya que las contraprestaciones exigidas y la propia gestión del programa (como cobrar el beneficio y garantizar la asistencia escolar y a controles de salud) comprometen el tiempo de las mujeres y las alejan del empleo formal y refuerzan su rol tradicional doméstico (Lopreite, 2012) (Comisión Económica para América Latina y el Caribe, 2010).

Lo anterior como lo menciona León, evidencia que «el empoderamiento de la mujer es un componente que en la retórica de las políticas con perspectiva de género se volvió polisémico (...), y a pesar del creciente interés como marco de análisis, los instrumentos e indicadores para monitorear y evaluar procesos de empoderamiento y sus resultados están en etapa incipiente» (León, 2013).

De acuerdo con estos limitantes consideramos el empoderamiento de la mujer como parte de ese núcleo indivisible sobre el que se deben inspirar y evaluar las políticas y los programas alimentarios, de ahí nuestro interés en la inclusión de esta dimensión como categoría de análisis en esta propuesta metodológica. Consideramos que las políticas deben estar formuladas con perspectiva de género es decir, buscar tener un impacto diferenciado en las mujeres, dependiendo del tipo de políticas y programas y de la edad de los y las titulares de derecho. Esta perspectiva se concretaría en por ejemplo proponerse la equidad en el estado nutricional de las niñas de diferentes condiciones socioeconómicas, introducir elementos de equidad de género en la formación, empoderar a las mujeres para la toma de decisiones sobre la distribución de los recursos al interior de los hogares, facilitar la participación social de las mujeres en las instancias de control social de las políticas y los programas y hacer exigencias a los padres para que el cumplimiento de las condicionalidades no sea sólo responsabilidad de las mujeres.

En síntesis se trata de que las políticas y los programas dinamicen los procesos que permitan organizar a las mujeres hacia una práctica transformadora, impulsen su liderazgo y destaquen su visibilidad dentro de su entorno. 


\subsection{Gestión del programa}

La gestión de una política o de un programa se refiere a los procesos y actividades llevadas a cabo durante todo el ciclo de construcción, implementación y evaluación. La gestión no es un momento específico dentro del ciclo de las políticas ni inicia con su formulación. Es decir, tiene que ver con la manera cómo se construye una agenda, se pone de relieve un problema y se define un curso de acción para resolverlo privilegiando la visión de ciertos actores y descartando otras posibilidades (Fernández-Arroyo \& Schejtman, 2012). En este sentido se trata de un proceso de contenido político más que técnico. Si bien en esta dimensión cabrían muchos aspectos, en esta propuesta priorizamos los siguientes: cómo se creó y cómo se definen los cambios en el programa (contexto político), la convergencia entre los objetivos de quienes formulan y dirigen la política y el programa y los de quienes lo desarrollan en el día a día, la transparencia en la asignación de los recursos, la existencia de procesos de seguimiento y evaluación y el uso a la información producida en la evaluación.

\section{Metodología}

Cavalcanti, clasifica la metodología de evaluación en tres grupos: 1) clásico, analítico o cuantitativo, 2) global, alternativo o cualitativo y 3) mixto (analítico global, clásico alternativo). El primer grupo es sustentado en paradigmas epistemológicos explicativos con posicionamientos objetivistas. El segundo grupo fue desarrollado con el fin de entender, interpretar y dar significado a las acciones y actividades que se desarrollan en los programas; estos modelos pueden ser también considerados como naturalistas y una de sus principales características es el énfasis del papel de los beneficiarios o participantes como agentes fundamentales para valorar lo que está siendo evaluado. El tercer grupo, abarca los modelos llamados mixtos ya que mezclan las características de los dos grupos anteriores al combinar información de naturaleza cuantitativa y cualitativa, además de tomar en cuenta las opiniones y percepciones de los usuarios de los programas (Cavalcanti, 2007). La metodología de nuestro diseño metodológico está fundamentada en este tercer grupo, como se describe a continuación:

\subsection{Metodología multidimensional y Triangulación de métodos}

En el presente diseño se utiliza un modelo mixto mediante una combinación de dos métodos: Metodología multidimensional y triangulación, que permite una mejor aproximación a las realidades sociales de los beneficiarios y de otros actores clave, además de la consideración de factores contextuales que pueden permear el impacto y la manera como se desarrolla el programa.

La metodología multidimensional fue creada inicialmente en el campo de la economía, posteriormente fue adaptada para el área de la salud por Donabedian y Tanaka, y para la evaluación de programas de seguridad alimentaria por Chávez y Pacheco (Chaves \& Pacheco, 2007). Esta metodología contempla la evaluación de tres categorías básicas, estructura, proceso y resultados.

La categoría estructura, incluye la identificación de los objetivos, los recursos, los instrumentos, las estructuras organizativas, burocráticas y técnicas, las formas de gestión y las posibilidades de control social con los que se haya diseñado el programa. 
El proceso, incluye el análisis del conjunto de actividades e intervenciones efectivamente desarrolladas para identificar si la forma en que se implementa el programa es adecuada para obtener los resultados esperados.

Los resultados, comprende la evaluación de los efectos concretos del programa en cada uno de las dimensiones evaluadas.

Dentro de los modelos que combinan lo cualitativo con lo cuantitativo se encuentra la triangulación de métodos. Usa los modelos cuantitativos fundamentados en la teorización del contexto y el contenido del programa a ser evaluado, con ayuda de instrumentos operacionales para analizar la productividad, los efectos y el rendimiento de la intervención, pero agrega la observación y el análisis de la dinámica de los actores sociales involucrados en el proceso; allí se comprende que los datos subjetivos y los datos objetivos son inseparables e interdependientes (De Souza, Goncalves de Assis, \& Ramos de Souza, 2005).

De acuerdo con Nirenberg et al, la triangulación se define como la combinación y el cruzamiento de diferentes puntos de vista, que identifican con mayor precisión la posición de un objeto. En las ciencias sociales se intenta mejorar la exactitud de los juicios y aumentar la confiabilidad de los resultados con la recolección de datos sobre el mismo fenómeno, desde diferentes perspectivas. Se busca asegurar el rigor y corregir la subjetividad de la evaluación, que supone la utilización de diferentes técnicas y fuentes para evaluar los mismos fenómenos o aspectos de la realidad con operaciones convergentes, en el sentido de síntesis y complementación metodológica (Nirenberg, Brawerman, \& Ruiz, 2003).

Por tanto, se conjuga la presencia de un evaluador externo, los abordajes cualitativos y cuantitativos, el análisis del contexto, de la historia, de las relaciones, y la participación de las personas. En ella, se amplía el espectro de las contribuciones teórico-metodológicas, de forma que se puedan evaluar las estructuras, la acción de los sujetos, los indicadores y las relaciones entre micro y macro realidades (Nirenberg, Brawerman, \& Ruiz, 2003).

La tabla 1 muestra la matriz de evaluación donde se muestra la combinación de ambas metodologías en las dimensiones a analizar.

\section{Consideraciones finales}

Este estudio se propuso construir una propuesta conceptual y metodológica para la evaluación de programas alimentarios y nutricionales poblacionales desde una perspectiva de equidad. La propuesta utiliza la metodología multidimensional para analizar la estructura, los procesos y los resultados y dimensiones que incluyen los logros del programa en el estado nutricional además de logros en procesos sociales y políticos.

Se trata de una propuesta que busca superar el énfasis de muchas de las evaluaciones realizadas hasta el momento, usualmente centrado en la cobertura, los costos, la focalización de los beneficiarios y los impactos biológicos en el estado nutricional. Se propone un análisis que triangule la información por actores, además de los datos cuantitativos y cualitativos. 
El análisis de la estructura y los procesos contribuye a explicar algunos de los resultados de los programas, para no limitarse solamente a presentar lo que está sucediendo, sino ir más allá: por qué está sucediendo. Por su parte la triangulación de información por participantes permite comprender las diferencias en las percepciones sobre el para qué del programa y el carácter y papel de los diferentes actores.

El mayor aporte de esta propuesta lo constituye la dotación de categorías y sus respectivos indicadores para juzgar si los programas nutricionales realmente están cumpliendo los objetivos que las políticas sociales actuales esperan de ellos, en relación con la promoción del desarrollo humano en la perspectiva de derechos. Estas metas requieren de una perspectiva más holística que esta propuesta ayuda a concretar.

El modelo propuesto comparte la metodología multidimensional, adaptada para el área de la salud por Donabedian y Tanaka, y para la evaluación de programas de seguridad alimentaria por Chávez y Pacheco (Chaves \& Pacheco, 2007), pero tiene como aportes específicos la propuesta para evaluar dimensiones que concretan los fundamentos que inspiran las nuevas políticas sociales.

Consideramos que a pesar de su aparente mayor complejidad la aplicabilidad práctica no reviste un esfuerzo considerable ya que en la mayoría de los casos los programas nutricionales poblacionales hacen parte de estrategias nacionales de lucha contra la pobreza en el marco de la promoción del desarrollo humano y cuentan con la infraestructura necesaria en términos de capacidad institucional y técnica. Eso significa un cuerpo profesional capacitado, con permanencia en el programa y documentación suficiente para conocer e interpretar su estructura y la mayoría de sus procesos. Igualmente por la importancia de estos programas usualmente generan procesos de participación y control social territorial que permite la confluencia de diferentes actores.

\section{Agradecimientos}

A los miembros de la Unidad de Análisis de Políticas Alimentarias y Nutricionales, y a la Escuela de Nutrición y Dietética de la Universidad de Antioquia-Colombia.

\section{Bibliografía}

Álvarez L, Pérez E, Goez J, Rivera A, Peña C. (2014). Métodos de evaluación de programas nutricionales de gran escala en América Latina: una revisión integrativa. Nutr Hosp. 2014; 31(01): 143-54.

Banco Mundial. (2004). Recuperado el 25 de Marzo de 2014, de Seguimiento y Evaluación: instrumentos, métodos y enfoques: Recuperado de www.worldbank.og/oed.ecd/

Bejarano-Roncancio, J. (2009). Contexto Alimentario y Nutricional. En J. BejaranoRoncancio, \& U. N. Colombia (Ed.), Fundamentos de Contratación Pública para proyectos sociales en Alimentación y Nutrición (págs. 11-45). Bogotá: Biblioteca Digital, Repositorio Institucional.

Bourges, H., Bengoa, J., \& O-Donell, M. (Sin fecha). Historias de la nutrición en América Latina. Recuperado el 25 de Marzo de 2014, Recuperado de http://www.sochinut. cl/pdf/HistNut_SLAN.pdf 
Cavalcanti, P. (2007). Sistematizando e comparando os enfoques de avaliação e de análise de políticas públicas: uma contribuição para a área educacional. Campinas, Brasil: Tesis doctoral.

Chac, M. C. (2008). Gobernanza y participación ciudadana en las politicas públicas frente al reto del desarrollo. Política y cultura, 9-37.

Chaves, S., \& Pacheco, L. (2007). Avaliação de políticas públicas de segurança alimentar e combate à fome no período de Evaluation of public policies for food security and hunger control in Brazil. Cadernos de Saúde Pública, 23(5), 1029-1040.

Comisión Económica para América Latina y el Caribe. (2010). ¿Qué Estado para qué igualdad? Conferencia Regional sobre la mujer de América Latina y el Caribe, (pág. 96). Brasilia.

Creswell, J. (2003). Research Desgin (Segunda edición ed.). (U. o. Nebraska, Ed.) Thousan Oaks: SAGE Publicationes.

De Souza, M., Goncalves de Assis, S., \& Ramos de Souza, E. (2005). Evaluación por triangulación de métodos. Abordaje de programas sociales. Buenos Aires: Lugar Editorial.

Departamento Nacional de Planeación - SINERGIA - Colombia. (2008). Evaluación de Políticas Públicas, Programa Familias en Acción. DNP, Bogotá.

Diaz, M. (2000). La evaluación de programas sociales: fundamentos y enfoques teóricos. Revista de investigación educativa, 18(2), 289-317.

Echeverry-Pinilla, A. (s.f.). Red de políticas públicas: Una mirada a la gestión territorial de las políticas públicas.

Fernández-Arroyo, N., \& Schejtman, L. (2012). Planificación de políticas, programas y proyectos sociales. CIPPEC y UNICEF, Buenos Aires.

Guba, E., \& Lincoln, Y. (1989). Fourth Generation Evaluation. Newbury Park: SAGE Publicationes.

Jenson, J. (2010). Diffusing Ideas for After Neoliberalism: The Social Investment Perspective in Europe and Latin America. Global Social Policy, 10(1), 59-84.

Jørgensen, S., \& Holzmann, R. (2003). Manejo Social del Riesgo: un nuevo marco conceptual para la protección social y más allá . Revista Facultad Nacional de Salud Pública, 21(1), 73-116.

Krause, W. (1963). La Alianza Para el Progreso. Journal of Interamerican studies, 5, 67-81.

Lechner, N. (2002). Los desafíos políticos del cambio cultural. Revista Nueva Sociedad, 184.

León, M. (10 de 11 de 2013).Poder y empoderamiento de las mujeres. Obtenido de Mujeres forjadoras de desarrollo: Recuperado de http://mujeresforjadorasdedesarrollo. files.wordpress.com/2013/11/m-lec3b3n-versic3b3n-final-nov-10-2013.pdf 
León, Magdalena (comp). (1998). Poder y empoderamiento de las mujeres. (U. N. Colombia, Ed.) Bogotá: Tercer Mundo Editores.

Lopreite, D. (2012). ¿Las mujeres y los niños primero? : nuevas estrategias de inversión social en América Latina. Revista Nueva Sociedad, 122-136.

Magalhães, R. (2014). Avaliação de políticas e iniciativas públicas de segurança alimentar e nutricional: dilemas e perspectivas metodológicas. Ciência \& Saúde Coletiva, 19(5), 1339-46.

Mancilla, L., Alvarez, L.-S., \& Pérez, E. (2012). Contexto histórico y descripción de los programas alimentarios y nutricionales. Medellín: Universidad de Antioquia.

Minayo, M., \& Cruz-Neto, O. (1999). Triangulación de métodos en la evaluación de programas y servicios de salud. En M. Bronfman, \& R. Castro, Salud, cambio social y política: perspectivas desde América Latina (págs. 65-80). Cor del Valle: Edamex.

Murguialday, C., Pérez, K., \& Eizagirre, M. (Sin fecha). Diccionario de Acción Humanitaria. Obtenido de Empoderamiento. Recuperado de http://www.dicc. hegoa.ehu.es/listar/mostrar/86

Naranjo-Giraldo, G., Lopera-Morales, J., \& Granada-Vahos, J. (2009). Las políticas públicas territoriales como redes de política pública y gobernanza local: la experiencia de diseño y formulación de las políticas públicas sobre desplazamiento forzado en el departamento de Antioquia y la ciudad de Medellín. 81-105.

Nirenberg, O., Brawerman, J., \& Ruiz, V. (2003). Evaluar para la transformación. Buenos Aires: Paidós.

Nuñez, J., \& Cuesta, L. (2007). ¿Cómo va "Bogotá sin hambre"? Universidad de los Andres, CEDE, Bogotá .

Ortegon, E., Pacheco, J., \& Prieto, A. (2005). Metodología del marco lógico para la planificación, el seguimiento y la evaluación de proyectos y programas . CEPAL, Santiago de Chile.

Ortiz, C., Isaza, C., \& Ramirez, G. (2010). 15 años del sistema nacional de evaluacion de gestión y resultados: Sinergia. SINERGIA, DNP, Bogotá.

Pautassi, L. (2009). Los difusos vínculos de articulación entre las políticas públicas y los derechos humanos. En J.-L. Vivero, X. Erazo, \& F. H. Dunant (Ed.), Derecho a la alimentación, políticas públicas e instituciones contra el hambre (pág. 333). Santiago de Chile: LOM Ediciones.

Rego, W.-L. (2008). Aspectos teóricos das políticas de ciudadania: Uma aproximaÇÃo ao bolsa família. Lua Nova, 73, 147-85.

República de Colombia. Departamento Nacional de planeación. (2007). Conpes social 113. Política Nacional de seguridad alimentaria y nutricional. Consejo Nacional de Política Económica Social, Bogotá. 
Romero, M., \& Díaz, I. (2002). Lo cuantitativo y lo cualitativo en la implementación de programas públicos sociales. Rev. Venezolana de Gerencia, 7(19), 442-461.

Roth, A.-N. (2009). La evaluación de políticas públicas en Colombia: una mirada crítica a partir de las prácticas evaluativas oficiales de los programas de la "Red de Apoyo Social”. Revista del CLAD Reforma y Democracia, 45, 7-9.

Serrano, C. (2005). La política social en la globalización. Programas de Protección en América Latina. Santiago de Chile: Comisión Económica para América Latina y el Caribe (CEPAL), Unidad Mujer y Desarrollo .

Velásquez, G. y. (2003). Qué ha pasado con la participación ciudadana en Colombia. Bogotá: Fundación Corona.

Vilas, C. (1997). De ambulancias, bomberos y policías: la política social del neoliberalismo. Desarrollo Económico, 36(144), 931-952.

Vivero, J.-L., \& Ramirez, P. (2009). Leyes, políticas e instituciones contra el hambre en el contexto Latinoamericano. En J.-L. Viveros, \& X. Erazo, Derecho a la alimentación. Políticas públicas e instituciones contra el hambre (págs. 41-74). Santiago de Chile: LOM Ediciones.

Weiss, C. (1995). Nothing as Practical as Good Theory: exploring theory-based evaluation for comprehensive community initiatives for children and family. En J. Connell, A. Kubisch, L. Schorr, \& C. Weiss, New Approaches to Evaluating Community Initiatives (págs. 65-93). Washington, D.C.: Aspen Institute. 


\section{Tabla1. Matriz de evaluación}

\begin{tabular}{|c|c|c|c|c|}
\hline Dimensión & Subdimensión & Estructura & Proceso & Resultado \\
\hline $\begin{array}{l}\text { Seguridad } \\
\text { alimentaria y } \\
\text { nutricional }\end{array}$ & $\begin{array}{l}\text { Estado } \\
\text { nutricional y de } \\
\text { salud }\end{array}$ & $\begin{array}{l}\text { El programa desde sus } \\
\text { lineamientos contempla: } \\
\text {-Los fundamentos de una } \\
\text { alimentación saludable que } \\
\text { promueve el adecuado } \\
\text { estado nutricional } \\
\text {-la satisfacción de los } \\
\text { requerimientos de los } \\
\text { grupos a quienes va dirigido } \\
\text { el programa dependiendo } \\
\text { del tiempo de permanencia } \\
\text { en la institución } \\
\text {-El mantenimiento de } \\
\text { adecuados estándares para } \\
\text { la preparación de alimentos } \\
\text {-Un sistema de monitoreo y } \\
\text { evaluación a la } \\
\text { alimentación entregada }\end{array}$ & $\begin{array}{l}\text { Seguimiento a la alimentación } \\
\text { entregada según la estrategia } \\
\text { desarrollada en el programa } \\
\text { centrada en las siguientes } \\
\text { características: alimentación } \\
\text { adecuada, balanceada, } \\
\text { controlada, moderada y variada, } \\
\text { de acuerdo a los de } \\
\text { requerimientos nutricionales. } \\
\text { Seguimiento al cumplimiento de } \\
\text { los estándares de preparación y } \\
\text { entrega efectiva de la } \\
\text { alimentación según las porciones } \\
\text { recomendadas de acuerdo los } \\
\text { requerimientos. } \\
\text { Monitoreo a los gustos y } \\
\text { rechazos de la alimentación } \\
\text { entregada y seguimiento al } \\
\text { consumo efectivo de la misma } \\
\text { por parte de los titulares de } \\
\text { derechos. } \\
\text { Indagación e inclusión de las } \\
\text { sugerencias y percepciones de }\end{array}$ & $\begin{array}{l}\text { Cambios en el estado nutricional de } \\
\text { los titulares de derechos } \\
\text { Indicadores antropométricos: } \\
\text { Menores de cinco años } \\
\text {-Peso/talla } \\
\text {-Talla/edad } \\
\text {-Perímetro cefálico } \\
\text {-Peso/edad } \\
5 \text { a } 18 \text { años } \\
\text {-Índice de masa corporal para la } \\
\text { edad } \\
\text {-Talla/edad } \\
\text {-Perimetro de cintura } \\
18 \text { a } 64 \text { años } \\
\text {-Índice de masa corporal } \\
\text {-Perímetro de cintura } \\
\text { Bioquímicos: } \\
\text { Menores de } 18 \text { años } \\
\text {-Hierro, perfil lipídico, hemoglobina, } \\
\text { vitamina A, glicemia, zinc } \\
\text { (especialmente en menores de } 5 \\
\text { años) }\end{array}$ \\
\hline
\end{tabular}




\begin{tabular}{|c|c|c|c|c|}
\hline Dimensión & Subdimensión & Estructura & Proceso & Resultado \\
\hline & & & $\begin{array}{l}\text { los titulares de derechos acerca } \\
\text { del desarrollo del programa } \\
\text { (preparación, entrega) y de la } \\
\text { alimentación recibida. }\end{array}$ & $\begin{array}{l}\text { Mayores de } 18 \text { años } \\
\text {-Hierro, perfil lipídico, hemoglobina, } \\
\text { glicemia }\end{array}$ \\
\hline & & & & $\begin{array}{l}\text { Percepción de los diferentes actores } \\
\text { sobre los cambios en el estado } \\
\text { nutricional. }\end{array}$ \\
\hline & \multirow{3}{*}{$\begin{array}{l}\text { Disponibilidad y } \\
\text { producción }\end{array}$} & $\begin{array}{l}\text { Los lineamientos del } \\
\text { programa promueven } \\
\text { proyectos productivos } \\
\text { sustentables de alimentos } \\
\text { que pretenden beneficiar a } \\
\text { los actores locales }\end{array}$ & $\begin{array}{l}\text { Los procesos de producción de } \\
\text { alimentos son respetuosos con el } \\
\text { medio ambiente. } \\
\text { Seguimiento a la producción de } \\
\text { alimentos saludables de calidady } \\
\text { para el autoconsumo de los } \\
\text { actores. }\end{array}$ & $\begin{array}{l}\text { Promoción de cambios que } \\
\text { privilegian la producción sustentable } \\
\text { en la que participen y se beneficien } \\
\text { los actores locales. } \\
\text { Indicador: } \\
\text { Obtención de alimentos saludables, } \\
\text { de mayor calidad nutritiva, no uso de } \\
\text { agrotóxicos, transgénicos, privilegio }\end{array}$ \\
\hline & & $\begin{array}{l}\text { Iniciativas plasmadas en los } \\
\text { lineamientos de los } \\
\text { programas para promover } \\
\text { la calidad de los alimentos } \\
\text { en la comercialización y } \\
\text { producción. }\end{array}$ & $\begin{array}{l}\text { Seguimiento a la } \\
\text { comercialización que se realiza } \\
\text { donde se verifique la } \\
\text { conservación de la calidad de los } \\
\text { alimentos }\end{array}$ & $\begin{array}{l}\text { de empaques respetuosos con el } \\
\text { medio ambiente, uso de semillas } \\
\text { autóctonas, aumento en la región } \\
\text { donde se esté implementando el } \\
\text { programa de la producción de } \\
\text { alimentos autóctonos. }\end{array}$ \\
\hline & & & & $\begin{array}{l}\text { Cambios en la calidad de los } \\
\text { alimentos que se comercializan y } \\
\text { producen. } \\
\text { Indicador: } \\
\text { Porcentaje de cambios en la } \\
\text { composición nutricional en alimentos } \\
\text { trazadores de riesgo, reducir o }\end{array}$ \\
\hline
\end{tabular}




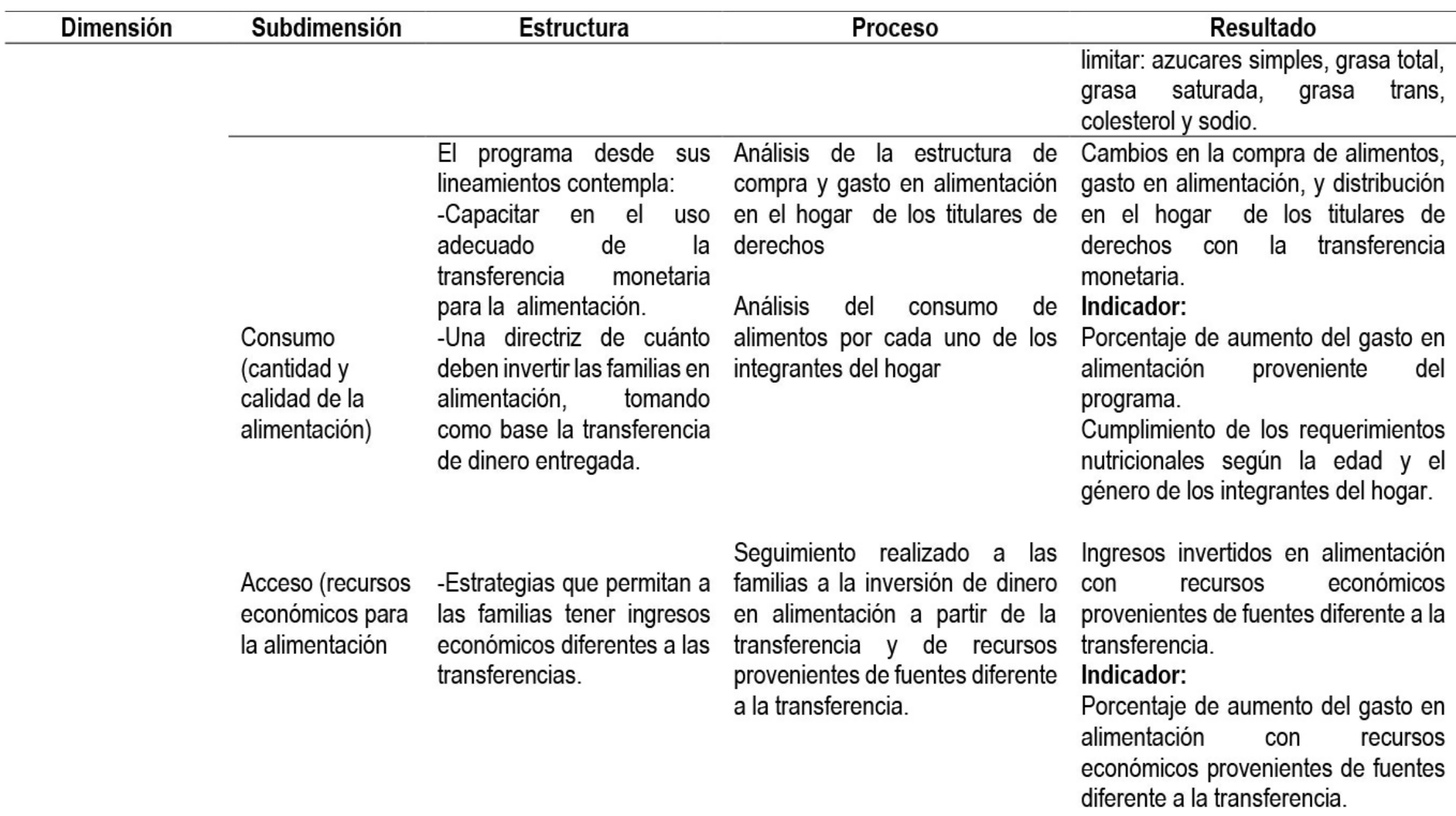




\begin{tabular}{|c|c|c|c|c|}
\hline Dimensión & Subdimensión & Estructura & Proceso & Resultado \\
\hline & $\begin{array}{l}\text { Prácticas } \\
\text { alimentarias }\end{array}$ & $\begin{array}{l}\text { El programa plantea desde } \\
\text { sus lineamientos la } \\
\text { formación a los titulares de } \\
\text { derechos para promover } \\
\text { cambios en sus } \\
\text { comportamientos y } \\
\text { prácticas en alimentación y } \\
\text { nutrición }\end{array}$ & $\begin{array}{l}\text { Seguimiento a las actividades } \\
\text { realizadas desde el programa } \\
\text { para promover el cambio en el } \\
\text { comportamiento de las personas } \\
\text { en sus prácticas alimentarias y } \\
\text { nutricionales }\end{array}$ & $\begin{array}{l}\text { Cambios en los conocimientos, } \\
\text { actitudes y prácticas a partir de la } \\
\text { participación en el programa. }\end{array}$ \\
\hline $\begin{array}{l}\text { El derecho a la } \\
\text { alimentación }\end{array}$ & & $\begin{array}{l}\text { El programa desde sus } \\
\text { lineamientos se plantea: } \\
\text {-Divulgar los bienes y } \\
\text { servicios que entrega y los } \\
\text { mecanismos de exigibilidad } \\
\text { de estos } \\
\text {-Que las condicionalidades } \\
\text { son una estrategia para la } \\
\text { realización de algunos } \\
\text { derechos sociales } \\
\text {-Desde un enfoque de } \\
\text { universalización y de } \\
\text { derechos }\end{array}$ & $\begin{array}{l}\text { Seguimiento a la atención que } \\
\text { realiza el programa para dar a } \\
\text { conocer sus bienes y servicios } \\
\text { como derechos y los } \\
\text { mecanismos de exigibilidad de } \\
\text { estos. } \\
\text { Seguimiento a la capacidad } \\
\text { institucional que tiene el } \\
\text { programa para articularse con las } \\
\text { instituciones proveedoras de las } \\
\text { condicionalidades para promover } \\
\text { servicios de educación y salud } \\
\text { desde una perspectiva de } \\
\text { derechos. } \\
\text { Seguimiento a los mecanismos } \\
\text { de inclusión del programa para } \\
\text { reducir los requisitos a los } \\
\text { titulares de derechos. }\end{array}$ & $\begin{array}{l}\text { Los titulares de derechos conocen los } \\
\text { bienes y servicios del programa y los } \\
\text { mecanismos de exigibilidad. } \\
\text { Las condicionalidades del programa } \\
\text { contribuyen a la realización de otros } \\
\text { derechos sociales (salud, educación). } \\
\text { Indicador: } \\
\text { Que otros derechos sociales logran } \\
\text { alcanzar los titulares de derechos por } \\
\text { medio del programa }\end{array}$ \\
\hline
\end{tabular}




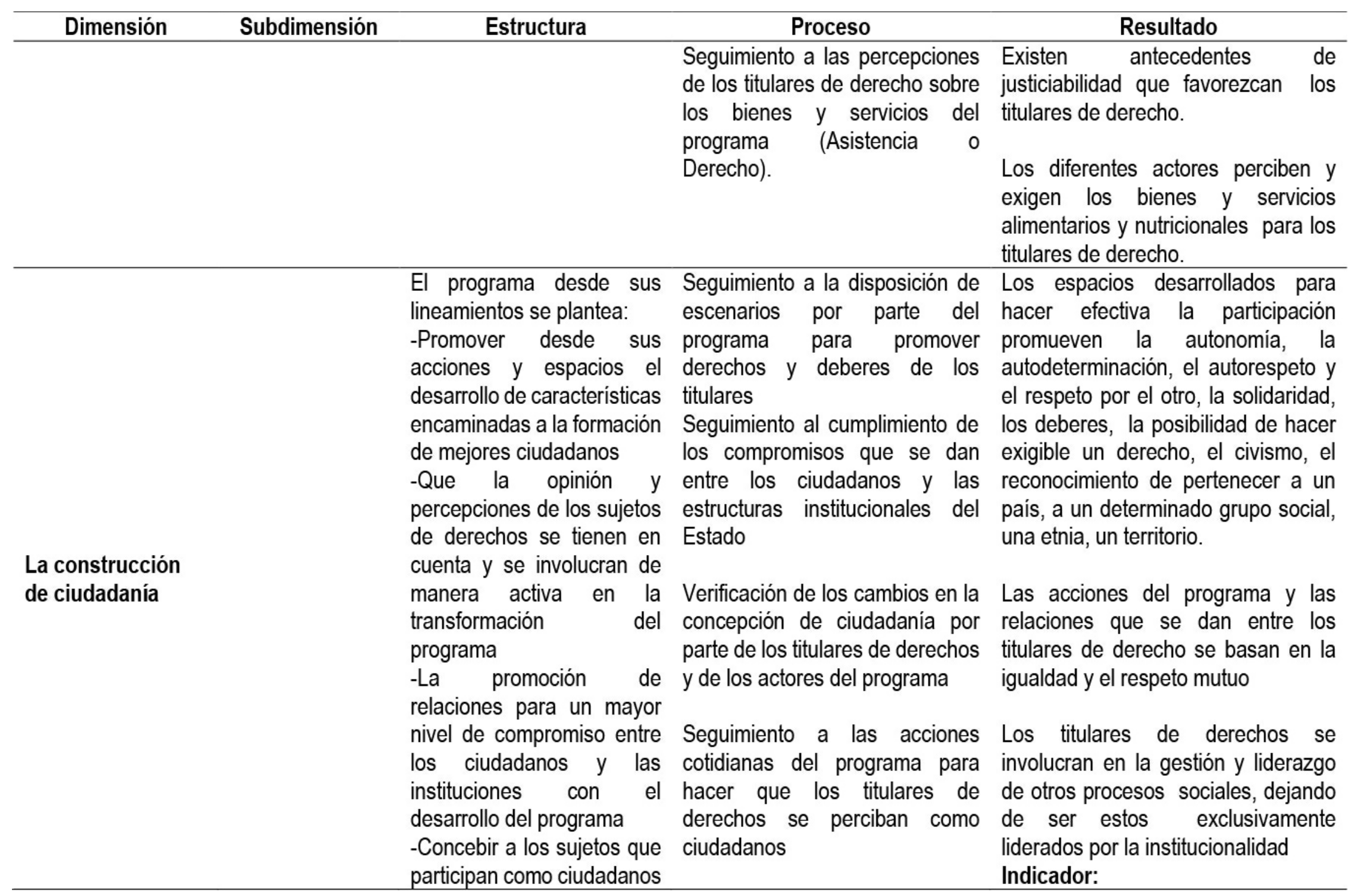




\begin{tabular}{|c|c|c|c|c|}
\hline Dimensión & Subdimensión & Estructura & Proceso & Resultado \\
\hline & & $\begin{array}{l}\text { que tienen derecho a la } \\
\text { alimentación de manera } \\
\text { universal y progresiva }\end{array}$ & $\begin{array}{l}\text { Seguimiento al nivel de } \\
\text { empoderamiento por parte de los } \\
\text { ciudadanos de los espacios y } \\
\text { acciones del programa, y de la } \\
\text { posibilidad de los mismos para } \\
\text { realizar otro tipo de gestiones en } \\
\text { la esfera social }\end{array}$ & $\begin{array}{l}\text { Cuantificar el número de proyectos y } \\
\text { de procesos en los que se involucran } \\
\text { los titulares de derecho y el tipo de } \\
\text { participación luego de ingresar al } \\
\text { programa. }\end{array}$ \\
\hline \multirow[t]{3}{*}{$\begin{array}{l}\text { Participación } \\
\text { ciudadana en las } \\
\text { políticas públicas }\end{array}$} & & \multirow{3}{*}{$\begin{array}{l}\text { El programa desde sus } \\
\text { lineamientos se plantea: } \\
\text {-la participación en el } \\
\text { diseño, ejecución y } \\
\text { evaluación, de los titulares } \\
\text { de derechos } \\
\text {-Realizar rendición de } \\
\text { cuentas a los titulares de } \\
\text { derechos sobre el uso y } \\
\text { distribución de los recursos } \\
\text {-Tener espacios de } \\
\text { participación y cogobierno } \\
\text { en todos los niveles }\end{array}$} & $\begin{array}{l}\text { Seguimiento a la participación } \\
\text { que realizan los titulares de } \\
\text { derechos en el diseño, ejecución } \\
\text { y evaluación del programa. }\end{array}$ & $\begin{array}{l}\text { Cambios en el programa a partir de la } \\
\text { participación de los titulares de } \\
\text { derechos } \\
\text { Indicador: } \\
\text { Numero de cambios y los tipos de } \\
\text { cambio producidos en el programa } \\
\text { con la participación de los titulares de } \\
\text { derechos }\end{array}$ \\
\hline & & & $\begin{array}{l}\text { Los titulares de derecho se } \\
\text { reúnen con regularidad, tienen } \\
\text { autonomía, vigilan el uso y } \\
\text { distribución de los recursos y } \\
\text { planean nuevas iniciativas con } \\
\text { miras a mejorar la prestación de } \\
\text { los servicios del programa }\end{array}$ & $\begin{array}{l}\text { Las estrategias de participación } \\
\text { promueven iniciativas desde la } \\
\text { comunidad } \\
\text { Indicador: } \\
\text { Número se estrategias promovidas } \\
\text { desde la comunidad en la que se } \\
\text { busque el mejoramiento de los } \\
\text { servicios del programa }\end{array}$ \\
\hline & & & $\begin{array}{l}\text { Seguimiento a las herramientas y } \\
\text { espacios que utiliza el programa } \\
\text { en los encuentros con los } \\
\text { titulares de derechos, para } \\
\text { fortalecer la identidad, la }\end{array}$ & $\begin{array}{l}\text { Existe una dinámica de participación } \\
\text { en el programa que transversaliza los } \\
\text { entes territoriales, locales y } \\
\text { nacionales. }\end{array}$ \\
\hline
\end{tabular}




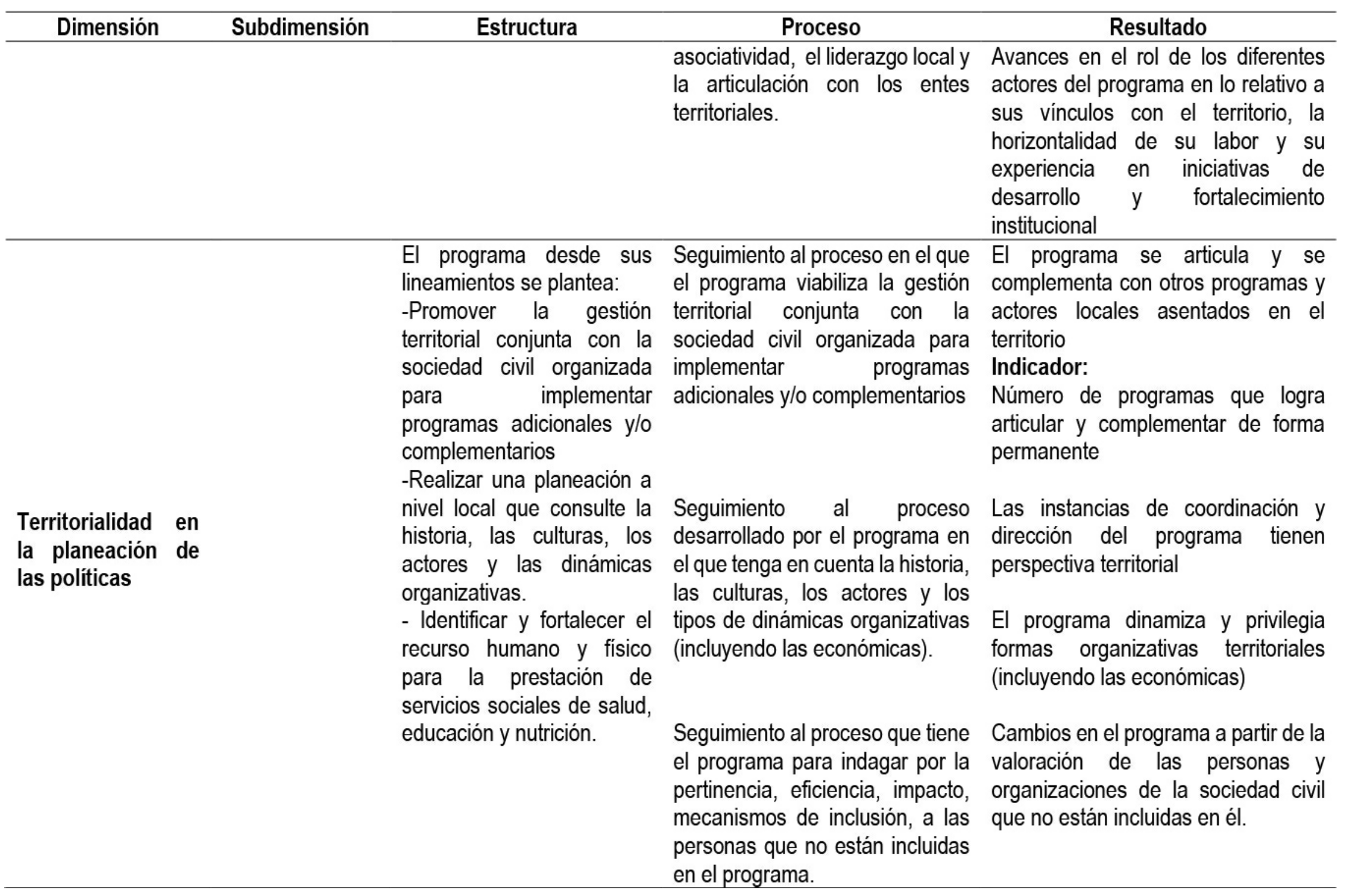




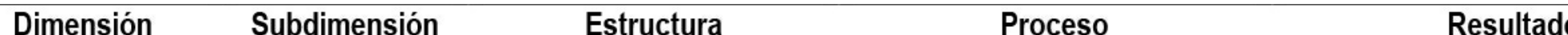

Seguimiento a la presencia de Recursos fisicos y humanos con los instituciones y el funcionamiento que se cuenta para que las personas de centros de atención en los que accedan a otros servicios se brindan servicios de salud, complementarios como salud, educación y nutrición, en el educación y nutrición en el territorio. territorio

El programa desde sus Seguimiento a las acciones que Las condicionalidades son exigidas lineamientos se plantea: realiza el programa para
-Estimular la participación asegurarse que durante la realiza el programa para por igual a padres y madres tanto de los padres como de asistencia a los programas de El programa promueve la las madres para dar salud, educación y nutrición participación social de las mujeres en cumplimiento a las participen tanto el padre como la las instancias de control social de las condicionalidades madre

-Promover la movilización, visibilización y acción Seguimiento a las actividades Porcentaje de participación de las colectiva de las mujeres. que el programa desarrolla para

Empoderamiento de la mujer
-Desarrollar estrategias que promover la movilización social promuevan

el que genera empoderamiento de

empoderamiento de la la mujer

mujer

-Desarrollar estrategias que promuevan equidad en roles y funciones entre mujeres y hombres -Aumentar la participación en el campo laboral y educativo de la mujeres

-Desarrollar sus acciones teniendo en cuenta los
El programa en sus actividades Las instancias de participación y diarias promueve una visión control del programa tienen paridad equitativa de los roles entre de genero mujeres y hombres

\section{Indicador:}

Asignación equitativa en las posibilidades de participación para las mujeres. 


\begin{tabular}{|c|c|c|c|c|}
\hline Dimensión & Subdimensión & Estructura & Proceso & Resultado \\
\hline & & $\begin{array}{l}\text { requerimientos y } \\
\text { necesidades de nutrientes } \\
\text { según el género y la edad. }\end{array}$ & $\begin{array}{l}\text { Seguimiento a las acciones que } \\
\text { realiza el programa para } \\
\text { diagnosticar la situación laboral y } \\
\text { educativa de la mujer, y los } \\
\text { mecanismos de capacitación y/o } \\
\text { articulación con otras } \\
\text { instituciones para facilitar la } \\
\text { inmersión en el mercado laboral } \\
\text { y/o mejorar el nivel educativo }\end{array}$ & $\begin{array}{l}\text { El programa promueve y facilita la } \\
\text { inserción en el mercado laboral y el } \\
\text { mejoramiento del nivel educativo de } \\
\text { las mujeres } \\
\text { Indicador: } \\
\text { Porcentaje de mujeres que ingresan } \\
\text { al mercado laboral o incrementan su } \\
\text { nivel educativo gracias al programa. }\end{array}$ \\
\hline & & & $\begin{array}{l}\text { Seguimiento a las acciones que } \\
\text { realiza el programa en cuanto al } \\
\text { cumplimiento de entrega de } \\
\text { alimentos y cómo estos se } \\
\text { adecuan a las necesidades de } \\
\text { nutrientes según el género y la } \\
\text { edad. } \\
\text { El programa realiza seguimiento } \\
\text { al estado nutricional de manera } \\
\text { diferenciada por género. }\end{array}$ & $\begin{array}{l}\text { El programa logra la equidad en el } \\
\text { estado nutricional de las titulares de } \\
\text { derechos de diferentes condiciones } \\
\text { socioeconómicas } \\
\text { Indicador: } \\
\text { Las mujeres y niñas que participan de } \\
\text { los programas logran un estado } \\
\text { nutricional adecuado según los } \\
\text { indicadores antropométricos. }\end{array}$ \\
\hline $\begin{array}{l}\text { Gestión del } \\
\text { programa }\end{array}$ & & $\begin{array}{l}\text { El programa desde sus } \\
\text { lineamientos se plantea: } \\
\text {-Tener un sistema de } \\
\text { monitoreo y evaluación } \\
\text {-Los mecanismos de } \\
\text { sostenibilidad financiera, la } \\
\text { distribución de sus recursos } \\
\text { y la progresividad de los } \\
\text { mismos en el tiempo }\end{array}$ & $\begin{array}{l}\text { Seguimiento al proceso en el que } \\
\text { se lleva a cabo la evaluación y } \\
\text { monitoreo } \\
\text { Seguimiento a las fuentes y a la } \\
\text { asignación de los recursos, así } \\
\text { como al presupuesto asignado } \\
\text { por año y a la ejecución del } \\
\text { mismo }\end{array}$ & $\begin{array}{l}\text { Cambios y decisiones del programa } \\
\text { a partir de la evaluación } \\
\text { Los recursos asignados al programa } \\
\text { aumentan progresivamente } \\
\text { Indicador: } \\
\text { Porcentaje de aumento de los } \\
\text { recursos y progresividad en los } \\
\text { mismos }\end{array}$ \\
\hline
\end{tabular}




\begin{tabular}{|c|c|c|c|c|}
\hline Dimensión & Subdimensión & Estructura & Proceso & Resultado \\
\hline & & $\begin{array}{l}\text {-Vigilar el cumplimiento de } \\
\text { los objetivos planteados por } \\
\text { parte de todos los actores } \\
\text { involucrados en la ejecución } \\
\text {-La autonomía y } \\
\text { descentralización en su } \\
\text { operacionalización y en el } \\
\text { uso transparente de los } \\
\text { recursos, pero que se } \\
\text { articula con estrategias } \\
\text { nacionales } \\
\text { departamentales }\end{array}$ & $\begin{array}{l}\text { Seguimiento a la autonomía en la } \\
\text { implementación del programa y } \\
\text { al uso transparente de los } \\
\text { recursos } \\
\text { Seguimiento a las acciones que } \\
\text { realiza el programa para } \\
\text { garantizar el cumplimiento de los } \\
\text { objetivos propuestos por parte de } \\
\text { todos los actores involucrados en } \\
\text { la ejecución } \\
\text { Seguimiento a la operación que } \\
\text { realiza el programa para } \\
\text { desarrollarse de manera } \\
\text { descentralizada pero coordinada } \\
\text { con los niveles municipal, } \\
\text { departamental o nacional. }\end{array}$ & $\begin{array}{l}\text { Gestión que realiza el programa y el } \\
\text { uso que le da a los recursos } \\
\text { Indicadores: } \\
\text {-Porcentaje de inversión que realiza } \\
\text { el programa para dar cumplimiento a } \\
\text { los objetivos } \\
\text {-Rendición de cuentas por año para } \\
\text { evaluar el uso transparente de los } \\
\text { recursos } \\
\text { Articulación entre los diferentes } \\
\text { directivos y operadores del programa } \\
\text { para el cumplimiento de los objetivos } \\
\text { Grado de descentralización } \\
\text { municipal, departamental o nacional y } \\
\text { autonomía del programa para } \\
\text { ejecutarse. } \\
\text { Indicador: } \\
\text { Independencia y autonomía en el } \\
\text { manejo de los recursos en los } \\
\text { diferentes niveles territoriales. }\end{array}$ \\
\hline
\end{tabular}

